\title{
Cytotoxic, anti-proliferative and apoptotic effects of noscapine on human estrogen receptor positive (MCF-7) and negative (MDA-MB-231) breast cancer cell lines
}

\author{
Kocak $\mathrm{C}^{1}$, Kocak FE${ }^{2}$, Ozturk B ${ }^{3}$, Tekin $\mathrm{G}^{4}$, Vatansev $\mathrm{H}^{3}$ \\ Department of Pathology, Faculty of Medicine, Usak University, Usak, Turkey. dcengizkocak@hotmail.com
}

\begin{abstract}
AIM: Noscapine, a naturally occurring alkaloid obtained from opium poppy, is a microtubule-targeting agent. This study is aimed to investigate the effects of noscapine on human breast cancer cell lines by comparing them with those of tamoxifen and docetaxel.

METHODS: MCF-7 and MDA MB-23 cell lines were used to observe the effects of docetaxel, tamoxifen, and noscapine on cell proliferation. For each drug, cell blocks were prepared from cultured cells treated with IC50 dose of each drug and these were examined histologically. The expressions of Ki-67, Bcl-2, BAX, and cyclin-D1 were assessed immunohistochemically.

RESULTS: Although noscapine showed cytotoxic effects on both cell lines in a time and dose dependent manner, MDA-MB-231 cells were more susceptible to its effects. Noscapine inhibited MCF-7 and MDAMB-231 cells proliferation in vitro with IC50 value of $29 \mu \mathrm{M}$ and $69 \mu \mathrm{M}$, respectively, which was comparable with IC50 of tamoxifen $(40 \mu \mathrm{M}$ and $50 \mu \mathrm{M})$ and docetaxel (43 nM and $32 \mathrm{nM})$. Noscapine showed antiproliferative effects by decreasing Ki-67, cyclin-D1 and apoptotic effects by increasing BAX/Bcl-2 ratio in both breast cancer cells. Its effect was comparable with tamoxifen and docetaxel.

CONCLUSION: Noscapine may be a good chemotherapeutic agent for the treatment of breast cancer, especially in estrogen receptor-negative breast cancer (Tab. 2, Fig. 7, Ref. 40). Text in PDF www.elis.sk. KEYWORDS: breast neoplasms, docetaxel, immunohistochemistry, MCF-7 cells, noscapine, tamoxifen.
\end{abstract}

\section{Introduction}

Breast cancer is the most common type of cancer in women, and its prevalence is gradually increasing every year. The second most common cause of cancer death in women is breast cancer after cervical cancer in developing countries, while in the developed countries, it is the most common cancer (1). There are several types of breast tumors according to the histological features including ductal carcinoma in situ, lobular carcinoma in situ, invasive ductal carcinoma, invasive lobular carcinoma, mucinous carcinoma, and papillary carcinoma. The invasive ductal carcinoma is the most common histological subtype of breast cancer (2). Depending on cellular and molecular heterogeneity, the breast tumors have various expression patterns of estrogen receptor (ER),

${ }^{1}$ Department of Pathology, Faculty of Medicine, Usak University, Usak, Turkey, ${ }^{2}$ Department of Medical Biochemistry, Faculty of Medicine, Kutahya Health Sciences University, Kutahya, Turkey, ${ }^{3}$ Department of Medical Biochemistry, Faculty of Medicine, Selcuk University, Konya, Turkey, and ${ }^{4}$ Department of Medical Services and Techniques Program of Medical Laboratory Techniques, Vocational School of Health Sciences, Selcuk University, Konya, Turkey

Address for correspondence: C. Kocak, MD, Department of Pathology, Faculty of Medicine, Usak University, 1 Eylul Campus, 64000, Usak, Turkey.

Phone: +90.276 .2212121$ progesterone receptor (PgR), and human epidermal growth factor receptor 2 (HER2; Human Genome Organisation, HUGO nomenclature ERBB2) (3).

In breast cancer, main therapeutic strategies are surgery, radiotherapy, adjuvant chemotherapy, and hormonotherapy (4). Approximately $70 \%$ of breast cancers are hormone receptor-positive and antiestrogen treatment strategies are recommended for this type of breast cancer (5). Highly effective estrogen antagonists, such as tamoxifen, are commonly used for the treatment of hormone-sensitive breast tumors (6). However, the loss of hormone receptors due to genetic variation of tumor cells or overexpression of drug efflux pumps lead to the development of resistance against hormone antagonists as well as other chemotherapeutic agents (7). On the other hand, approximately $10-17 \%$ of breast cancers are negative for ER, PgR, and HER2 expressions. These breast cancers are referred to as triple negative breast cancer (TNBC). TNBC is a most aggressive breast tumor and an important clinical problem because of their relatively poor prognosis, aggressive behavior and lack of targeted therapies $(8,9)$. TNBCs are often unresponsive to endocrine agents such as tamoxifen and less responsive to standard adjuvant therapy. Furthermore, no specific targeted therapy for improving the prognosis and survey is available in patients with TNBC (10). A promising target for the treatment of these tumors are the microtubule-interfering agents such as taxanes and vinca alkaloids (11). However, these 
cancers are highly resistant to chemotherapeutic approach because of drug resistance due to mutations. Therefore, alternative strategies have been developed against this heterogeneous group of breast cancer $(12,13)$.

Despite the currently used treatment strategies, there is still no effective cure for patients with breast cancer, especially hormone-resistant breast cancer (14). Therefore, the discovery and the development of more efficacious and less cytotoxic drugs would improve survival outcome of patients with breast cancer. Noscapine is a naturally occurring phthalideisoquinoline alkaloid obtained from opium poppy, orally available, antitussive drug (15). In 1954, noscapine was found to display cytotoxic in vitro activity (16). However, in a subsequent study, it failed to show any considerable in vivo anti-tumour effects (17). Thus, further studies were not carried out to investigate its effect on treating cancer and noscapine was ignored for 40 years until rediscovering its anticancer effects by Joshi et al (18). They found that noscapine binds to tubulin, alters its conformation, suppresses the dynamics of microtubule assembly, and blocks cell cycle progression at mitosis followed by apoptotic cell death. Furthermore, in a subsequent study, they reported that compared with other microtubule drugs, noscapine also showed little or no toxicity to body organs and inhibited no primary humoral immune responses in mice (19). Further studies have shown that noscapine inhibits the growth of various cultured tumor cells and tumors implanted in nude mice (20-22).

Anticancer effect of noscapine has been reported by several previous studies on breast cancer, yet, according to the best of our knowledge, no studies have explored the anticancer effect of noscapine as well as itsmechanisms by comparing it with those of docetaxel and tamoxifen. Therefore, in this study, we aimed to investigate the effects of noscapine on hormone-sensitive MCF-7 and hormone-insensitive MDA-MB-231 human breast cancer cell lines. In the light of the potential therapeutic effects of noscapine, it is important to clarify the effect mechanisms of these compounds. Thus, histopathological examinations and immunohistochemical staining methods were used to understand the underlying molecular effect mechanisms of noscapine in this study. In addition, the effects of noscapine were also compared with those of antiestrogenic drug tamoxifen and anti-microtubule drug docetaxel.

\section{Materials and methods}

\section{Chemicals}

Chemical compounds studied in this article: Noscapine (PubChem CID: 275196), Docetaxel (PubChem CID: 148124), Tamoxifen (PubChem CID: 2733525)

Noscapine, tamoxifen and docetaxel were purchased from Sigma-Aldrich (Sigma-Aldrich Co LLC, St.Louis, MO, USA). The noscapine, tamoxifen and docetaxel were dissolved in DMSO (Sigma-Aldrich). Noscapine and tamoxifen stored as $1000 \mu \mathrm{mol} / \mathrm{L}$ and docetaxel stored as $1000 \mathrm{nmol} / \mathrm{L}$ stock solutions at $80^{\circ} \mathrm{C}$ until use. For all in vitro assays, the compounds were diluted to concentrations ranging from $12.5 \mu \mathrm{mol} / \mathrm{L}$ to $100 \mu \mathrm{mol} / \mathrm{L}$ for noscapine and tamoxifen, and $12.5 \mathrm{nmol} / \mathrm{L}$ to $100 \mathrm{nmol} / \mathrm{L}$ for docetaxel. The human breast cancer cell lines, MDA-MB-231 and MCF-7, were obtained from American Type Culture Collection (ATCC, Manassas, VA, USA).

\section{Cell lines and cell cultures}

The human breast cancer cell lines, MCF-7 and MDA MB23 , were used to observe the effects of docetaxel, tamoxifen, and noscapine on cell proliferation and estimate IC50 values. The MCF7 and MDA-MB-231 cell lines were cultured following the recommend protocols from American Type Culture Collection (ATCC, Manassas, VA, USA). The cells were cultured in 10\% fetal bovine serum containing Dulbecco's Modified Eagle Medium (DMEM, Sigma-Aldrich) at $37{ }^{\circ} \mathrm{C}$ in a humidified atmosphere containing $5 \% \mathrm{CO}_{2}$. The cell culture media contained antibiotic solution of penicillin $(5,000 \mathrm{U} / \mathrm{mL})$, streptomycin $(0.1 \mathrm{mg} / \mathrm{mL})$, and neomycin $(0.2 \mathrm{mg} / \mathrm{mL})$. After seeding the cell suspensions in DMEM into the plate, cells were monitored every $15 \mathrm{~min}$ at a period of $72 \mathrm{~h}$ (MCF7), $56 \mathrm{~h}$ (MDA MB-231) for docetaxel, $48 \mathrm{~h}$ (MCF-7 and MDA MB-231) for tamoxifen, and $70 \mathrm{~h}$ (MCF-7 and MDA MB-231) for noscapine. Twenty-four $\mathrm{h}$ after seeding, the cells were treated with 4 different doses of docetaxel, tamoxifen, and noscapine.

\section{Cell viability assay}

The cytotoxic effects of docetaxel, tamoxifen, and doscapine on the breast cancer cell lines (MCF-7 and MDA-MB-231) were analyzed by xCELLigence system (Roche Diagnostics $\mathrm{GmbH}$, Penzbeerg, Germany) and the IC50 values were obtained from xCELLigence system (Roche Diagnostics).

\section{Preparation of cell blocks}

For each drug, cell blocks were prepared from cultured cells treated with the IC50 dose of each drug. Cultured cells were harvested using a sterile cell scraper without enzymatic treatment. Culture supernatant was removed and discarded. Cells were fixed using $90 \%$ ethyl alcohol and $10 \%$ neutral buffered formalin for $30 \mathrm{~min}$ at room temperature. Then, cells were transferred into a sterile conical eppendorf tube and centrifuged at $2000 \mathrm{x} \mathrm{rpm}$ for $5 \mathrm{~min}$. The pellet from the bottom of the tube was blocked into a cassette using a cytoblock kit (Shandon Cytoblock Cell Block Preparation System, Thermo Fisher Scientific Inc., Cheshire, UK). The blocked cassette was fixed using $10 \%$ neutral buffered formalin for $12 \mathrm{~h}$ at room temperature, then embedded in paraffin.

\section{Histopathological and immunohistochemical stainings}

Formalin-fixed paraffin-embedded breast cancer cells were examined histopathologically using haematoxylin and eosin (H\&E) stain. Cell blocks were sectioned at a $4-\mu \mathrm{m}$ thickness using a semiautomated rotary microtome (Leica RM2245, Leica Microsystems Inc., Bannockburn, IL, USA). The sections were stained with hematoxylin and eosin (H\&E) with an automated side stainer and cover slipper (Tissue-Tek Prisma/Film, Sakura Finetek Inc., CA, USA). Then, the slides were examined under a light microscope (Olympus BX51, Tokyo, Japan). Formalin-fixed paraffin-embedded blocks were sectioned (4- $\mu \mathrm{m}$ thick) for immunohistochemical analysis. Immunohistochemical staining was performed on an automated immunohistochemistry slide staining system (Roche Ventana Bench- 
Mark GX, Ventana Medical Systems, Inc., Tucson, AZ, USA). Ki67 (rabbit monoclonal primary antibody, clone 30-9, Roche), Bcl-2 (rabbit monoclonal primary antibody, clone SP66, Roche), CyclinD1 (rabbit monoclonal primary antibody, clone SP4-R, Roche), and BAX (rabbit polyclonal primary antibody, Dako) were analyzed on whole formalin-fixed paraffin-embedded cell block sections. For negative controls, the primary antibodies were omitted.

\section{Assessment of H\&E and immunohistochemical stainings}

Untreated cells were used as control. H\&E-stained slides were examined under a light microscope (Olympus BX51). The numbers of cells were counted from randomly selected 10 fields under x 400 magnification and mean of counted cells from 10 fields were calculated. The immunohistochemical expressions of the analyzed proteins (Ki-67, Bcl-2, BAX, and cyclin-D1) were assessed under a light microscope (Olympus BX51). The number of positive cells per 100 was calculated from randomly selected fields. Quantification of the analyzed proteins was peformed by using the percentage of positive cells.

\section{Statistical analysis}

Statistical analyses were performed using GraphPad Prism version 6.05 (GraphPad Software, Inc., CA, USA). The comparisons of histopathological and immunohistochemical scoring values were analyzed using Chi-square test. A p $<0.05$ was considered statistically significant.

\section{Results}

Cytotoxic and antiproliferative effect of noscapine on MCF-7 and MDA-MB-231 cell lines

All examined drugs inhibited the proliferation of cell lines in a time- and dose-dependent manner and all drugs showed cytotoxic effects on both cell lines. IC50 values for examined drugs were calculated for both cell line types. The cell viability assays showed that IC50 value of noscapine was lower for MCF-7 cells $(29 \mu \mathrm{M}$ at $66 \mathrm{~h})$ in comparison with MDA MB-231 cells $(69 \mu \mathrm{M}$ at $66 \mathrm{~h})$ (Figs 1A-B). IC50 value of tamoxifen was lower for MCF-7 cells $(40 \mu \mathrm{M}$ at $41 \mathrm{~h})$ in comparison with MDA MB-231 cells $(50 \mu \mathrm{M}$ at $45 \mathrm{~h}$ ) (Figs 1A-B). IC50 value of docetaxel was lower for MDA MB-231 cells (32 $\mathrm{nM}$ at $60 \mathrm{~h}$ ) in comparison with MCF-7 cells (43 $\mathrm{nM}$ at $40 \mathrm{~h}$ ) (Figs $1 \mathrm{~A}-\mathrm{B})$. The H\&E staining examinations revealed that MCF-7 cells showed less susceptibility to noscapine and docetaxel. Noscapine caused a greater decrease in the number of MDA-MB-231 cells compared to the number of MCF-7 cells in H\&E stained slides. The MCF-7 cells were more susceptible to tamoxifen which caused a greater decrease in the number of MCF-7 cells compared to the number of MDA-MB-231 cells (Figs 2A-B, 3A-B). Immunohistochemical examinations demonstrated that noscapine and docetaxel caused a greater decrease in the percentage of Ki-67 and cyclin-D1-positive MDA-MB-231 cells compared to the percentage of Ki-67-positive MCF-7 cells. Tamoxifen caused a greater decrease in the percentage of Ki-67 and cyclin-D1-positive MCF-7 cells (Figs 2A-B, 4A-B, 5A-B). Thus, noscapine and docetaxel had a greater anti-proliferative effect on MDA-MB-231 cells, whereas, tamoxifen had a greater anti-proliferative effect on MCF-7 cells.

\section{ApoptoticeffectofnoscapineonMCF-7andMDA-MB-231 celllines}

Noscapine and docetaxel caused a greater decrease in the percentage of Bcl-2-positive MDA-MB-231 cells and a greater increase in the percentage of BAX-positive MDA-MB-231 cells. Tamoxifen caused a greater decrease in the percentage of $\mathrm{Bcl}$-2-positive and a grater increase in the percentage of BAX-positive MCF-7 cells (Figs 2A-B, 6A-B, 7A-B). Thus, while noscapine and docetaxel had a greater apoptotic effect on MDA-MB-231
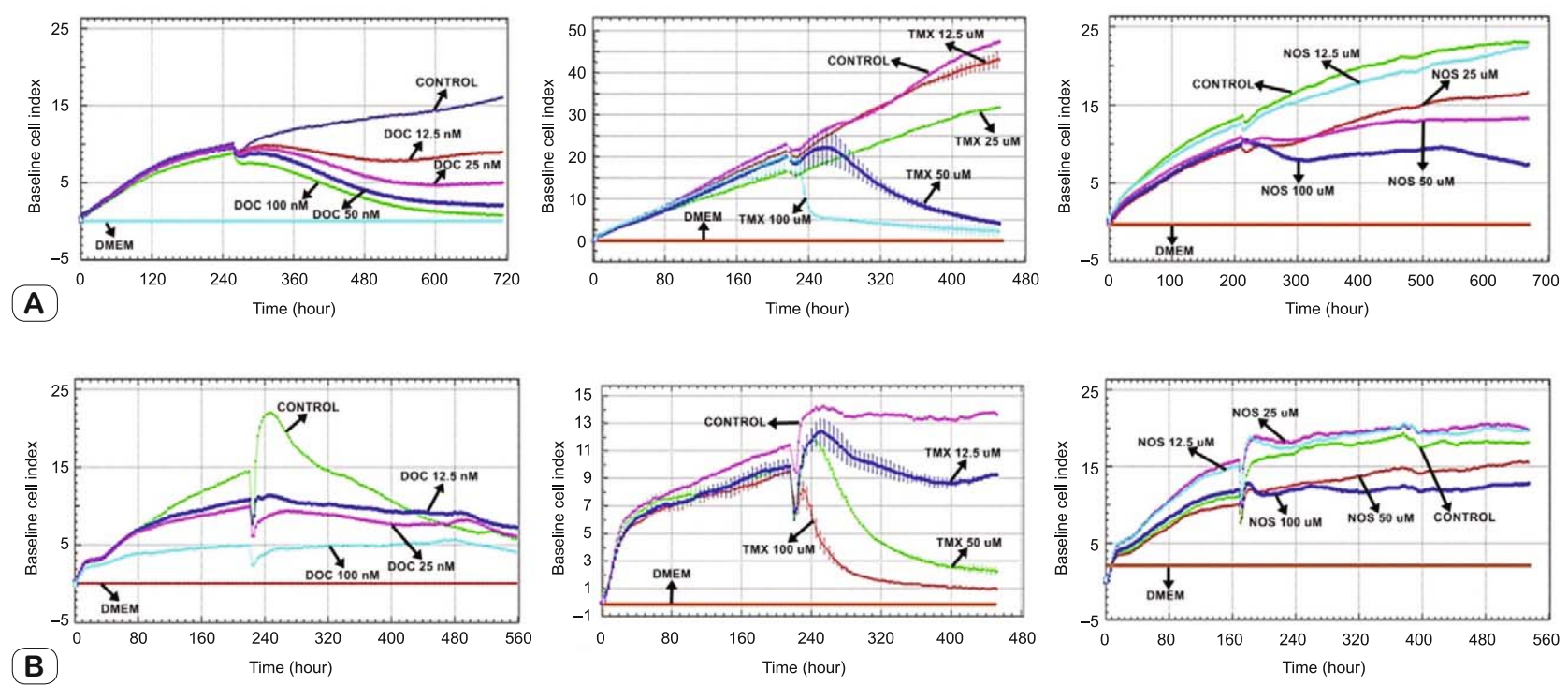

Fig. 1. A. The proliferation graph of MCF-7 cells treated with docetaxel, tamoxifen, and noscapine. B. The proliferation graph of MDA-MB-231 cells treated with docetaxel, tamoxifen, and noscapine. 

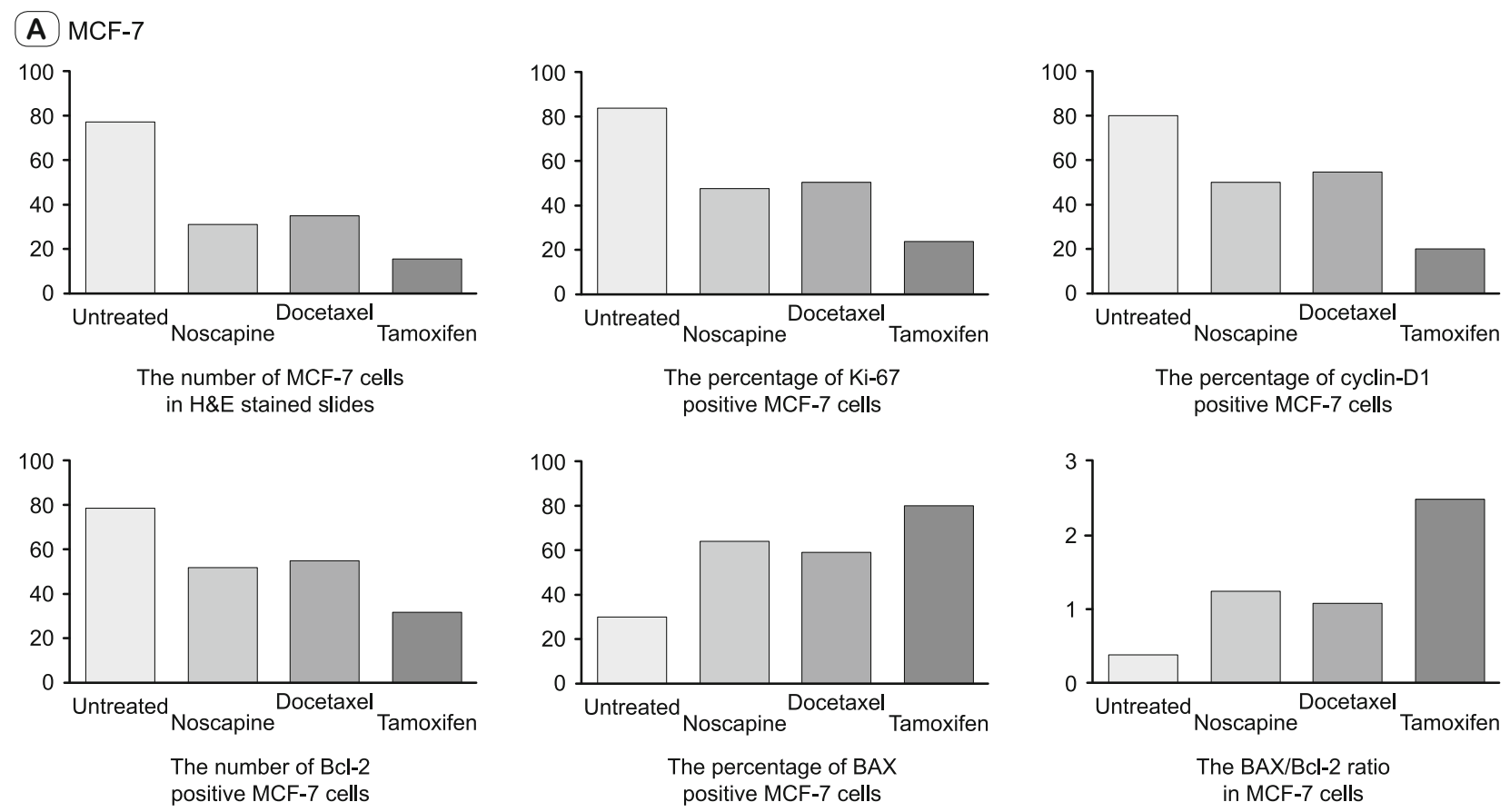

\section{(B) MDA-MB-231-7}
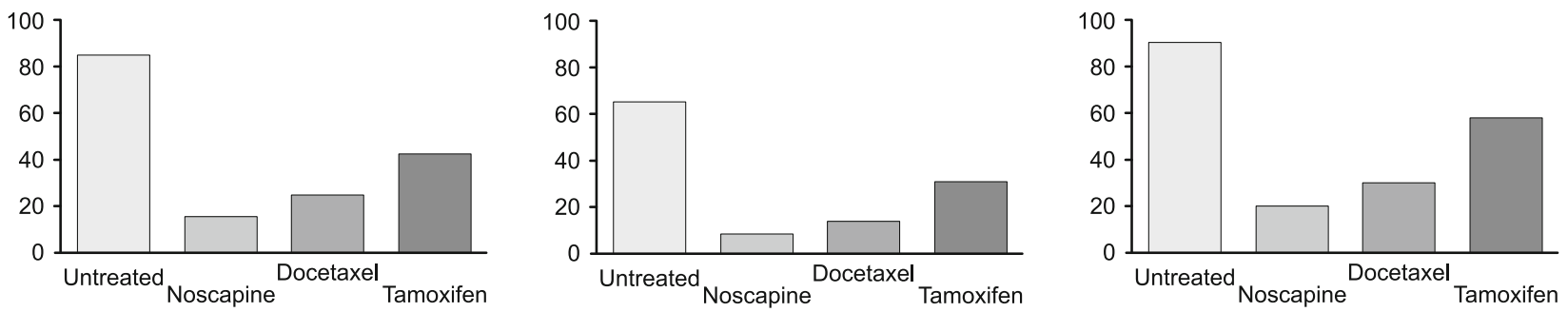

The number of MDA-MB-231 cells in H\&E stained slides
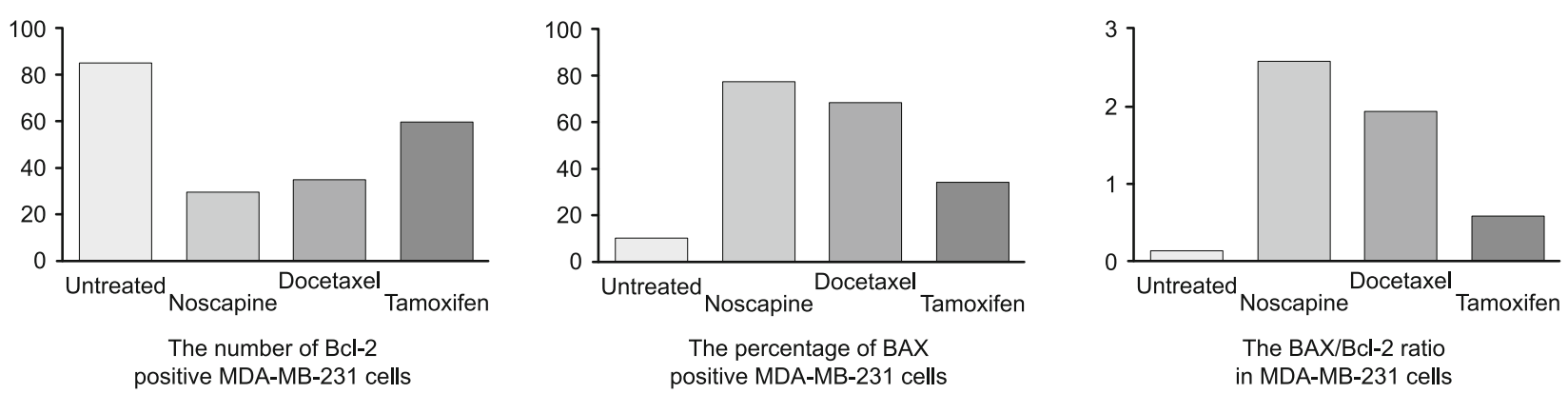

Fig. 2. A. The percentage of Ki-67, Bcl-2, BAX, cyclin-D1 positive MCF-7 cells and the number of MCF-7 cells in H\&E stained slides. B. The percentage of Ki-67-, Bcl-2-, BAX-, and cyclin-D1-positive MDA-MB-231 cells and the number of MDA-MB-231 cells in H\&E stained slides.

cells than on MCF-7 cells, tamoxifen had a greater apoptotic effect on MCF-7 cells.

The differences among untreated cells and examined drug-treated cells for histopathological and immunohistochemical scoring values

In both cell lines, the differences among untreated cells and examined drug-treated cells for histopathological and immunohisto- chemical scoring values are demonstrated in Table 1. The comparison of H\&E ( $p<0.001$, MCF-7; $<<0.001$, MDA-MB-231), Bcl-2 $(\mathrm{p}<0.001, \mathrm{MCF}-7 ; \mathrm{p}<0.001$, MDA-MB-231), BAX $(\mathrm{p}<0.001$, MCF-7; $<<0.001$, MDA-MB-231), BAX/Bcl-2 ( $<<0.001$, MCF7 ; $<<0.001$, MDA-MB-231), Ki-67 ( $p<0.001$, MCF-7; $p<0.001$, MDA-MB-231), and cyclin-D1 ( $<<0.001, \mathrm{MCF}-7$; $\mathrm{p}<0.001$, MDA-MB-231) scoring values by Chi-square test demonstrated 

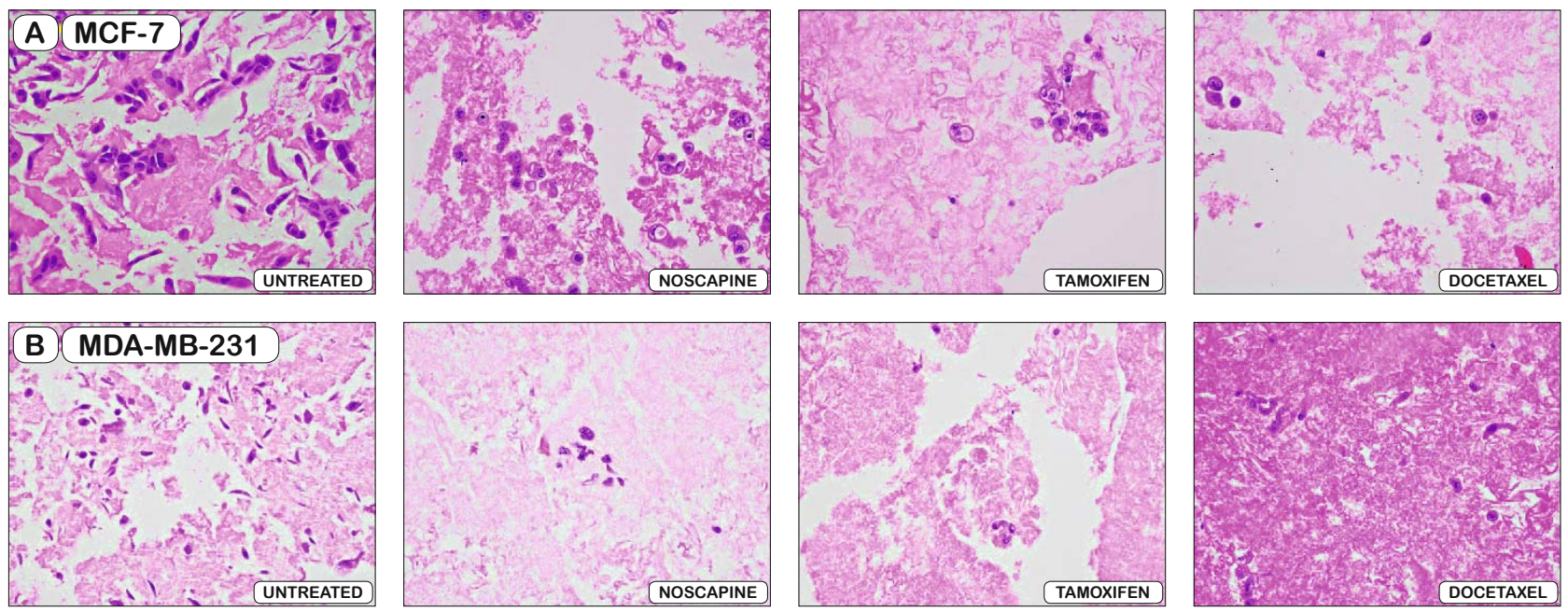

Fig. 3. A. Photomicrograph showing H\&E stained untreated, docetaxel-treated, tamoxifen-treated, and noscapine-treated MCF-7 cells. B. Photomicrograph showing H\&E stained untreated, docetaxel-treated, tamoxifen-treated, and noscapine-treated MDA-MB-231 cells (H\&E x 400).
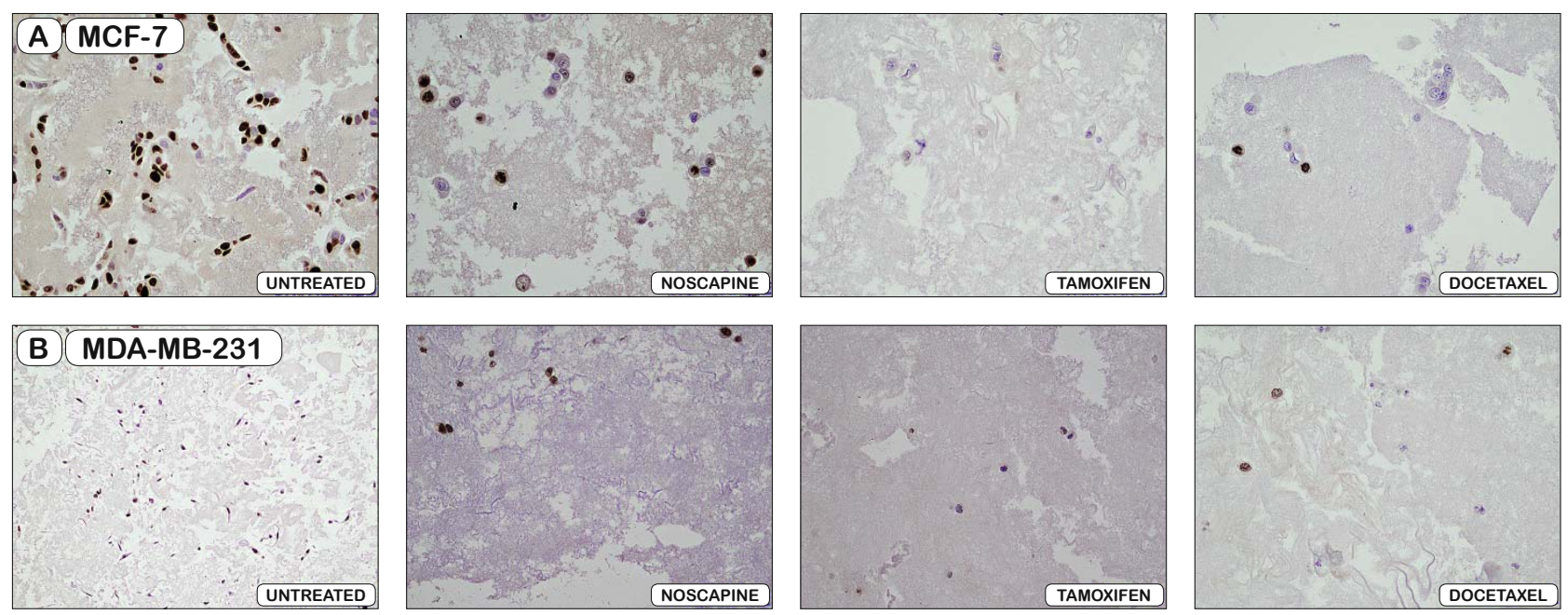

Fig. 4. A. Photomicrograph showing Ki-67 positive untreated, docetaxel-treated, tamoxifen-treated, and noscapine-treated MCF-7 cells. B. Photomicrograph showing Ki-67-positive untreated, docetaxel-treated, tamoxifen-treated, and noscapine-treated MDA-MB-231 cells (Ki-67 x 400 ).
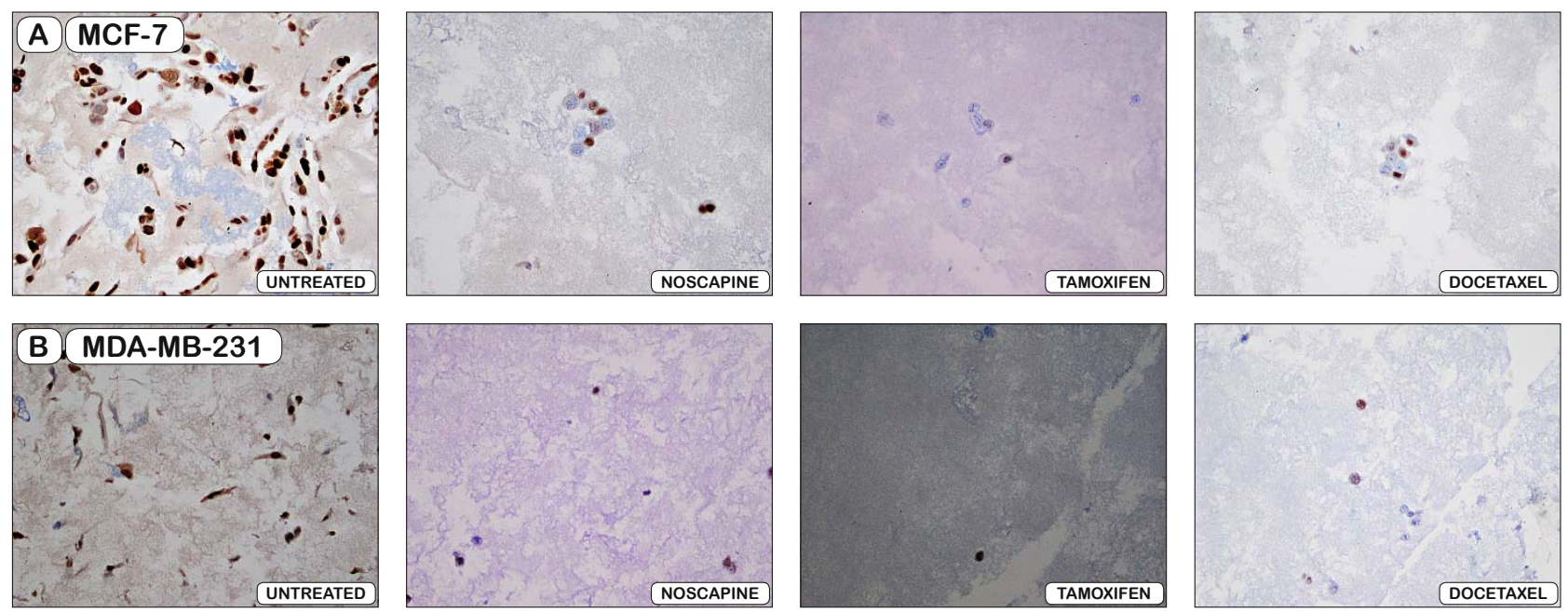

Fig. 5. A. Photomicrograph showing Bcl-2 positive untreated, docetaxel-treated, tamoxifen-treated, and noscapine-treated MCF-7 cells. B. Photomicrograph showing Bcl-2-positive untreated, docetaxel-treated, tamoxifen-treated, and noscapine-treated MDA-MB-231 cells (Bcl-2 x 400). 

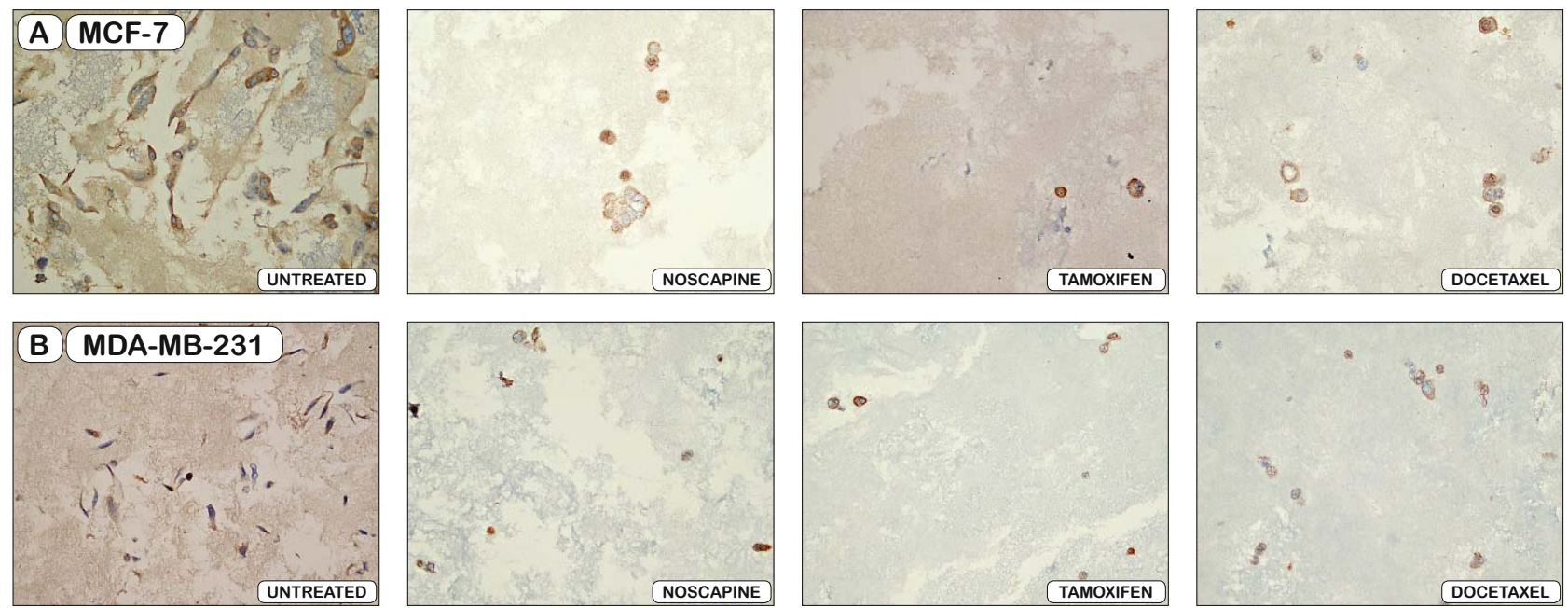

Fig. 6. A. Photomicrograph showing BAX positive untreated, docetaxel-treated, tamoxifen-treated, and noscapine-treated MCF-7 cells. B. Photomicrograph showing BAX-positive untreated, docetaxel-treated, tamoxifen-treated, and noscapine-treated MDA-MB-231 cells (BAX x 400).
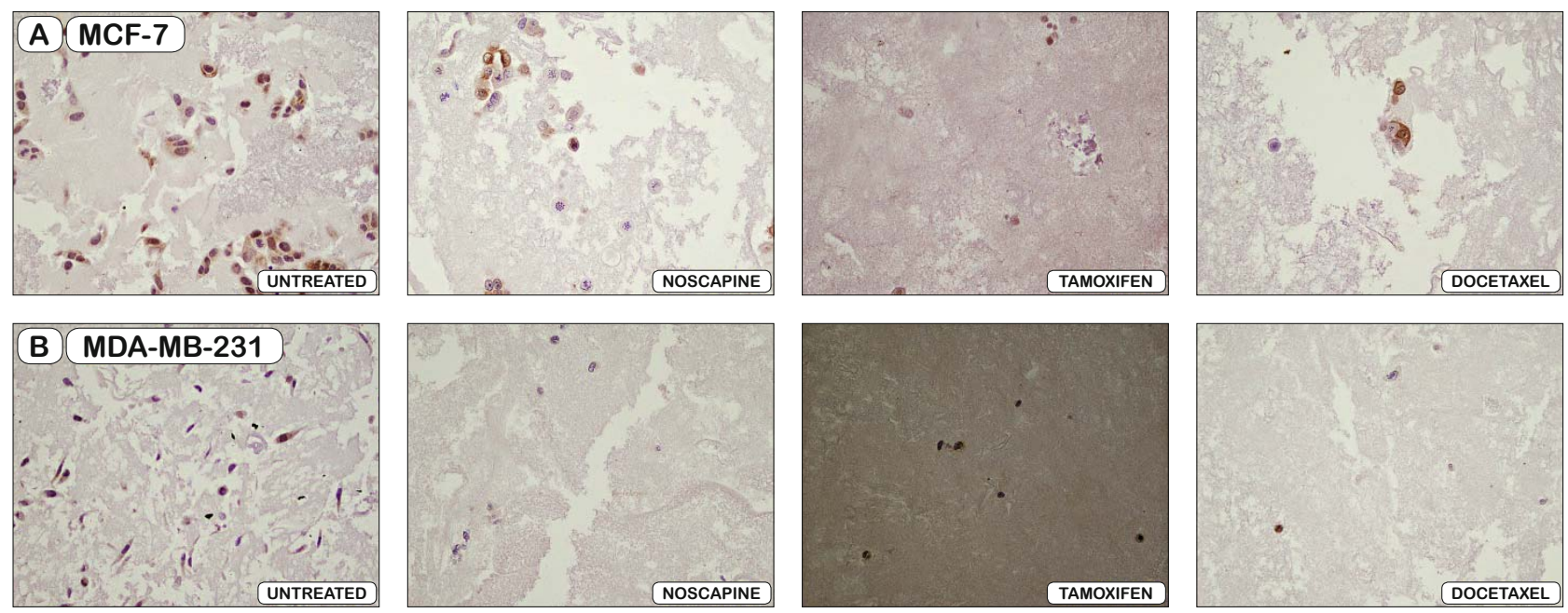

Fig. 7. A. Photomicrograph showing cyclin-D1 positive untreated, docetaxel-treated, tamoxifen-treated, and noscapine-treated MCF-7 cells. B. Photomicrograph showing cyclin-D1-positive untreated, docetaxel-treated, tamoxifen-treated, and noscapine-treated MDA-MB-231 cells (Cyclin-D1 x 400).

significant differences among untreated cells, docetaxel-, tamoxifen-, and noscapine-treated cells. In addition, we compared the examined drug-treated cells without untreated cells for histopathological and immunohistochemical scoring values (Tab. 2). The comparison of $\mathrm{H} \& \mathrm{E}(\mathrm{p}=0.03, \mathrm{MCF}-7$; $p<0.001$, MDA-MB-231), Bcl-2 ( $\mathrm{p}=0.03, \mathrm{MCF}-7 ; \mathrm{p}=0.003$, MDA-MB-231), BAX ( $\mathrm{p}=$ 0.17, MCF-7; $<<0.001$, MDA-MB-231), BAX/Bcl-2 (p $<0.001$, MCF-7; $<<0.001$, MDA-MB-231), Ki-67 ( $\mathrm{p}=0.004$, MCF-7; $\mathrm{p}$ $<0.001$, MDA-MB-231), and cyclin-D1 ( $<<0.001$, MCF-7; $\mathrm{p}<$ 0.001 , MDA-MB-231) scoring values showed significant differences among docetaxel-, tamoxifen-, and noscapine-treated cells.

\section{Discussion}

To our knowledge, this is the first study that demonstrates the effectiveness of noscapine against human estrogen receptor-positive
(MCF-7) and receptor-negative (MDA-MB-231) breast cancer cell lines by comparing it with that of tamoxifen and docetaxel. Cytotoxic effects of noscapine were evident via cell viability assays. The findings obtained from cell viability assays revealed that noscapine had a significant anti-proliferative effect on MCF-7 and MDAMB-231 human breast cancer cell lines. However, the pattern of cytotoxicity in these two cell lines was different and the cytotoxic activity of noscapine was dependent on time, dose, type and sensitivity of cancer cells. We demonstrated that noscapine inhibits MCF-7 and MDA-MB-231 cells in vitro proliferation with IC50 value of $29 \mu \mathrm{M}$ and $69 \mu \mathrm{M}$, respectively, which was comparable with IC50 of tamoxifen $(40 \mu \mathrm{M}$ and $50 \mu \mathrm{M})$ and docetaxel (43 nM and $32 \mathrm{nM}$ ). The histopathologic and immunohistochemical examination of cancer cells corroborated the cell viability assay results. Histopathologic and immunohistochemical examination revealed that noscapine had apoptotic and as well as antiproliferative effects 
on both breast cancer cells. These findings suggest that noscapine can inhibit the cellular proliferation and induce apoptosis of breast cancer cells irrespective of their receptor status. Therefore, noscapine may be an effective anticancer agent due to antiproliferative as well as apoptotic effects in the treatment of breast cancers.

Despite recent advances in treatment, breast cancer is still the leading cause of death by cancer in women worldwide. The etiology of this neoplasm is complex and genetic factors contribute to is complex etiology (23). Therefore, cancer studies are focused on finding novel anticancer agents with greater efficacy and lesser side effects in the cure of breast cancer. The effectiveness of microtubule-interfering agents in cancer therapy has been validated by the use of taxanes and vinca alkaloids for the treatment of a variety of cancers (24). The clinical usage of taxanes has been limited by the emergence of drug-resistance and toxicities. Furthermore, currently available anti-microtubule drugs have to be infused intravenously during extended period of time due to the use of cremophor as a vehicle to minimize the risk of hypersensitivity reaction $(24,25)$. For these reasons, there is still the need for discovering novel microtubule-targeting drugs with lower toxicity and higher efficacy in the treatment of breast cancers.

Noscapine, a phthalideisoquinoline alkaloid of opium, is a drug with low toxicity, very few side effects, and good tolerance $(15,17,19)$. The discovery of noscapine as a potent antitumor agent was surprising, because noscapine has been used medicinally as an antitussive. Noscapine binds tubulin subunits, alters the tubulin assembly, arrests cells in mitosis and causes apoptosis in cycling cells. Rather than affecting microtubule polymerization, noscapine alters steady-state dynamics of microtubule assembly, while lengthening the time that microtubules spend in an attenuated state (26). It has been found that even at high concentrations, noscapine did not alter the tubulin polymer/monomer ratio in $\mathrm{HeLa}$ cells (27). This weak interaction makes it safer to use than other microtubule-targeting agents (14). As noscapine is water-soluble and absorbed after oral administration, it has advantage over many other drugs for cancer therapy $(15,18)$. Noscapine is distinguished from other microtubule-targeted agents by its lack of considerable cytotoxicity to normal cells (28). In a recent study by QuisbertValenzuela et al (29), the apoptotic effect of noscapine on breast cancer cell lines (MCF-7, MDA-MB-231) was investigated by comparing it to that on a normal breast cell line (MCF-10F). Their results revealed that noscapine had lower toxicity in normal cells and was an effective anticancer agent. In another study (30), selective cytotoxic and apoptotic effects of noscapine were investigated on HT29, T47D and HT1080 cancer cell lines by comparing them with that on NIH3T3 non-cancerous cells. Noscapine had dosedependent selective cytotoxic and apoptotic effects on cancer cell lines and no cytotoxic effect on noncancerous NIH-3 T3 cells. The authors commented that noscapine acts by a mechanism of kinetic stabilization by binding to a different site of tubulin when compared to other known tubulin-binding agents and although noscapine's binding to tubulin site is not very strong, micromolar concentrations are adequate to arrest the cell cycle. Therefore, this feature may explain the selective cytotoxicity of noscapine. In a number of studies, anti-proliferative effect of noscapine on various cancer types including many drug-resistant variants have been reported (19-22, 24, 25, 31-34). The antimitotic effect of noscapine triggers cell apoptosis in cancer cells, the mechanism of which is poorly understood (14). Apoptotic effects of noscapine on tumor cells have been previously documented in several studies $(7,19,29$, 34-36). Currently, clinical trials have been conducted on treating non-Hodgkin's lymphoma, chronic lymphocytic leukemia, and multiple myeloma with noscapine $(37,38)$.

In agreement with the findings of this study, the antitumor effect of noscapine and noscapine analogs in breast cancer has been previously reported by several studies $(7,18,22,39,40)$. In a study by Aneja et al (7), a synthetic analogue of noscapine, 9-bromonoscapine, inhibited cell proliferation and induced apoptosis following G-M arrest in MDA-MB-231 and MCF-7 human breast cancer cells in a dose-dependent manner. The 9-bromonoscapine analogue increased BAX levels, decreased Bcl-2 levels and Bcl-2/BAX ratio. In addition, 9-bromonoscapine significantly inhibited growth of human breast (MDA-MB-231) xenograft tumor implanted in nude mice, without any detectable toxicity in tissues. In another similar study (18), noscapine inhibited cell proliferation in MCF-7 breast cancer cells and the IC50 value was $42 \mu \mathrm{M}$. Furthermore, noscapine regressed the size of human breast (MCF-7) xenograft tumor implanted in nude mice by inducing apoptosis. Chougule et al (22) reported that noscapine inhibited proliferation of MDA-MB-231 and MDA-MB-468 cells with the IC50 values of 36 and $42 \mu \mathrm{M}$, respectively. In addition, oral administration of noscapine reduced the tumor volume by decreasing the expression of anti-apoptotic genes and increasing that of apoptotic genes in MDA-MB-231 xenografts, without any weight loss or other signs of toxicity in mice. In another study (39), noscapine inhibited proliferation of MCF-7 and MDA-MB-231 cells with the IC50 values of 15 and $20 \mu \mathrm{M}$, respectively in a dose-dependent manner. Furthermore, noscapine had a greater cytotoxic effect on breast cancer stem cells derived from both cell lines compared with their parental cells and cancer stem cells were more sensitive to noscapine in comparison with the whole population in both cell lines. The apoptotic effect of noscapine on MDA-MB-231 cancer stem cells was greater than on parent cells, whereas the MCF-7 cancer stem cells were less affected than parent cells. In another study, halogenated noscapine analogs inhibited the proliferation of breast cancer cells (MCF-7, MDA-MB-231) (40).

In conclusion, we suggest that noscapine inhibits the cellular proliferation and induces apoptosis in both hormone-insensitive and hormone-sensitive breast cancer cells., However, it has a more profound effect on hormone-insensitive breast cancer cells. Thus, noscapine may be a good chemotherapeutic agent for the treatment or clinical management of breast cancer, especially hormone-insensitive breast cancer.

\section{References}

1. Bayraktar B, Yilmaz E, Bayraktar O et al. Distribution of HLA antigens in breast cancer. Bratisl Lek Listy 2012; 113 (6): 372-375.

2. Balazsi M, Blanco P, Zoroquiain P, Levine MD, Burnier MN Jr. Invasive ductal breast carcinoma detector that is robust to image magnification in whole digital slides. J Med Imaging (Bellingham) 2016; 3 (2): 027501. 
3. Sørlie T, Perou CM, Tibshirani R et al. Gene expression patterns of breast carcinomas distinguish tumor subclasses with clinical implications. Proc Natl Acad Sci U S A 2001; 98 (19): 10869-10874.

4. Bange J, Zwick E, Ullrich A. Molecular targets for breast cancer therapy and prevention. Nat Med 2001; 7 (5): 548-552.

5. Yardley DA. Pharmacologic management of bone-related complications and bone metastases in postmenopausal women with hormone receptorpositive breast cancer. Breast Cancer (Dove Med Press) 2016; 8: 73-82.

6. Bentrem DJ, Jordan VC. Role of antiestrogens and aromatase inhibitors in breast cancer treatment. Curr Opin Obstet Gynecol 2002; 14 (1): $5-12$.

7. Aneja R, Zhou J, Zhou B, Chandra R, Joshi HC. Treatment of hormone-refractory breast cancer: apoptosis and regression of human tumors implanted in mice. Mol Cancer Ther 2006; 5 (9): 2366-2377.

8. Irvin WJ Jr, Carey LA. What is triple-negative breast cancer? Eur J Cancer 2008; 44 (18): 2799-2805.

9. Kassam F, Enright K, Dent R et al. Survival outcomes for patients with metastatic triple-negative breast cancer: implications for clinical practice and trial design. Clin Breast Cancer 2009; 9 (1): 29-33.

10. Buzdar AU. Advances in endocrine treatments for postmenopausal women with metastatic and early breast cancer. Oncologist 2003; 8 (4): 335-341.

11. Cabral F. Factors determining cellular mechanisms of resistance to antimitotic drugs. Drug Resist Updat 2001; 4 (1): 3-8.

12. Chopin V, Toillon RA, Jouy N, Le Bourhis X. p21(WAF1/CIP1) is dispensable for G1 arrest, but indispensable for apoptosis induced by sodium butyrate in MCF-7 breast cancer cells. Oncogene 2004; 23 (1): 21-29.

13. Turgut Cosan D, Oner C, Mutlu Sahin F. Micro RNA-126 coordinates cell behavior and signaling cascades according to characteristics of breast cancer cells. Bratisl Lek Listy 2016; 117 (11): 639-647.

14. Tripathi M, Reddy PL, Rawat DS. Noscapine and its analogues as anti-cancer agents. J Chem Biol Interfaces 2014; 4 (1): 1-22.

15. Mahmoudian M, Rahimi-Moghaddam $P$. The anti-cancer activity of noscapine: a review. Recent Pat Anticancer Drug Discov 2009; 4 (1): 92-97.

16. Lettre H. Synergists and antagonists of mitotic poisons. Ann N Y Acad Sci 1954; 58 (7): 1264-1275.

17. Eagle H, Foley GE. Cytotoxicity in human cell cultures as a primary screen for the detection of anti-tumor agents. Cancer Res 1958; 18 (9): $1017-1025$.

18. Ye K, Ke Y, Keshava $\mathbf{N}$ et al. Opium alkaloid noscapine is an antitumor agent that arrests metaphase and induces apoptosis in dividing cells. Proc Natl Acad Sci 1998; 95 (4): 1601-1606.

19. Ke Y, Ye K, Grossniklaus HE, Archer DR, Joshi HC, Kapp JA. Noscapine inhibits tumor growth with little toxicity to normal tissues or inhibition of immune responses. Cancer Immunol Immunother 2000; 49 (4-5): 217-225.

20. Joshi HC, Zhou J. Noscapine and analogues as potential chemotherapeutic agents. Drug News Perspect 2000; 13 (9): 543-546.

21. Zhou J, Gupta K, Aggarwal S et al. Brominated derivatives of noscapine are potent microtubule-interfering agents that perturb mitosis and inhibit cell proliferation. Mol Pharmacol 2003; 63 (4): 799-807.

22. Chougule MB, Patel AR, Jackson T, Singh M. Antitumor activity of Noscapine in combination with Doxorubicin in triple negative breast cancer. PLoS One 2011; 6 (3): e17733.
23. Iorio MV, Casalini P, Piovan C, Braccioli L, Tagliabue E. Breast cancer and microRNAs: therapeutic impact. Breast 2011; 20 Suppl 3: S63-70.

24. Chougule M, Patel AR, Sachdeva P, Jackson T, Singh M. Anticancer activity of Noscapine, an opioid alkaloid in combination with Cisplatin in human non-small cell lung cancer. Lung Cancer 2011; 71 (3): 271-282.

25. Jackson T, Chougule MB, Ichite N, Patlolla RR, Singh M. Antitumor activity of noscapine in human non-small cell lung cancer xenograft model. Cancer Chemother Pharmacol 2008; 63 (1): 117-126.

26. Rida PC, LiVecche D, Ogden A, Zhou J, Aneja R. The Noscapine Chronicle: A Pharmaco-Historic Biography of the Opiate Alkaloid Family and its Clinical Applications. Med Res Rev 2015; 35 (5): 1072-1096.

27. Zhou J, Panda D, Landen JW, Wilson L, Joshi HC. Minor alteration of microtubule Dynamics causes loss of tension across kinetochore pairs and activates the spindle checkpoint. J Biol Chem 2002; 277 (19): 17200-17208.

28. Lopus M, Naik PK. Taking aim at a dynamic target: Noscapinoids as microtubule-targeted cancer therapeutics. Pharmacol Rep 2015; 67 (1): $56-62$.

29. Quisbert-Valenzuela EO, Calaf GM. Apoptotic effect of noscapine in breast cancer cell lines. Int J Oncol 2016; 48 (6): 2666-2674.

30. Afzali M, Ghaeli P, Khanavi M et al. Non-addictive opium alkaloids selectively induce apoptosis in cancer cells compared to normal cells. Daru 2015; 23: 16.

31. Landen JW, Lang R, McMahon SJ et al. Noscapine alters microtubule dynamics in living cells and inhibits the progression of melanoma. Cancer Res 2002; 62 (14): 4109-4114.

32. Zhou J, Gupta K, Yao J et al. Paclitaxel-resistant human ovarian cancer cells undergo c-jun NH2-terminal kinase-mediated apoptosis in response to noscapine. J Biol Chem 2002; 277 (42): 39777-39785.

33. Landen JW, Hau V, Wang $M$ et al. Noscapine crosses the bloodbrain barrier and inhibits glioblastoma growth. Clin Cancer Res 2004; 10 (15): 5187-5201.

34. Aneja R, Ghaleb AM, Zhou J, Yang VW, Joshi HC. P53 and p21 determine the sensitivity of noscapine-induced apoptosis in colon cancer cells. Cancer Res 2007; 67 (8): 3862-3870.

35. Heidari N, Goliaei B, Rahimi-Moghaddam P, Rahbar-Roshandel N, Mahmoudian M. Apoptotic Pathway induced by noscapine in human myelogenous leukemic cells. Anti-Cancer Drugs 2007; 18 (10): 1139-1147.

36. Newcomb EW, Lukyanova Y, Simirnova I, Schnee T, Zagzag D. Noscapine induces apoptosis in human glioma cells by an AIF dependent pathway. Anti-Cancer Drugs 2008; 19 (6): 553-563.

37. https://clinicaltrials.gov/ct2/show/ NCT00912899?term=CB3304 \&rank $=1$.

38. https://clinicaltrials.gov/ct2/show/ NCT00183950?term=noscapi ne\&rank=2.

39. Sajadian S, Vatankhah M, Majdzadeh M, Kouhsari SM, Ghahremani MH, Ostad SN. Cell cycle arrest and apoptogenic properties of opium alkaloids noscapine and papaverine on breast cancer stem cells. Toxicol Mech Methods 2015; 25 (5): 388-395.

40. Aneja R, Va ngapandu SN, Lopus M et al. Synthesis of microtubuleinterfering halogenated noscapine analogs that perturb mitosis in cancer cells followed by cell death. Biochem Pharmacol 2006; 72 (4): 415-426.

Received June 18, 2019. Accepted August 5, 2019. 